\title{
Th1 cytokines, true functional signatures for protective immunity against TB?
}

\author{
Gucheng Zeng ${ }^{1}$, Guoliang Zhang ${ }^{2}$ and Xinchun Chen $^{3}$
}

The lack of an effective preventative vaccine against tuberculosis (TB) presents a great challenge to TB control. Since it takes an extremely long time to accurately determine the protective efficacy of TB vaccines, there is a great need to identify the surrogate signatures of protection to facilitate vaccine development. Unfortunately, antigen-specific Th1 cytokines that are currently used to evaluate the protective efficacy of the TB vaccine, do not align with the protection and failure of TB vaccine candidates in clinical trials. In this review, we discuss the limitation of current Th1 cytokines as surrogates of protection and address the potential elements that should be considered to finalize the true functional signatures of protective immunity against TB.

Cellular and Molecular Immunology (2018) 15, 206-215; doi:10.1038/cmi.2017.113; published online 20 November 2017

Keywords: protective immunity; tuberculosis; vaccine

\section{INTRODUCTION}

In the past 50 years, accumulating evidence has demonstrated that $\mathrm{T}$ cells play critical roles in host defense against $\mathrm{Myco-}$ bacterium tuberculosis (Mtb) infection. An insufficient T-cell response renders the host unable to clear Mtb and therefore results in the establishment of persistent Mtb infection. In both systematic and aerosol-challenged murine TB models, $\mathrm{T}$ cells were shown to be required for host protective immunity against TB. $^{1-3}$ While $\mathrm{CD} 8+\mathrm{T}$ cells play a critical role in mediating immune protection against $\mathrm{TB}$, the protective role of $\mathrm{T}$ cells was initially shown to be mainly mediated by CD4 $\mathrm{T}$ cells (Figure 1). ${ }^{4,5}$ Interestingly, CD4+ cells can act as innatelike cells to contain the very early extrapulmonary dissemination of $\mathrm{Mtb}$ and slow down the rapid progression of TB. Protective roles against TB can possibly be attributed to CD4+ cells' master helper function to sustain the systemic and pulmonary anti-TB responses of CD8+ $\mathrm{T}$ cells and CD3non-T lymphocytes. ${ }^{6}$ In agreement with these findings, clinical observations suggested that HIV-1-induced loss of CD4 T cells renders $\mathrm{TB}$ susceptibility and increases reactivation of latent $\mathrm{Mtb}$ infection, further highlighting the importance of $\mathrm{T}$ cells in defense against $\mathrm{TB}^{7,8}$
After encountering the Mtb antigen presented by antigenpresenting cells (APCs), naive CD4 $\mathrm{T}$ cells differentiate into effector and/or memory cells. Depending on the specificity and affinity of TCR, availability of cognate Mtb antigens, costimulation signaling, and so on, naive CD4 $\mathrm{T}$ cells can be differentiated into various subsets, including at least Th1, Th2, Th17, Treg and $\mathrm{T}_{\mathrm{FH}}$ cells. Among these subsets, IFN- $\gamma$ producing Th1 cells are accepted as the major population that mediates protective immunity against TB. Indeed, mice deficient in Th1 cytokines (for example, IFN- $\gamma$, IL-12p40) succumbed early to Mtb infection with high bacillus loads. ${ }^{9-11}$ Furthermore, mice with defects in IFN- $\gamma$-dependent enzymes show a similar susceptible phenotype. ${ }^{12-15}$ Rapid clonal expansion, pulmonary trafficking and the accumulation of many PPD Ag-specific IFN- $\gamma+\mathrm{CD} 4+$ and few CD8+ T effector cells in BCG-vaccinated macaques upon pulmonary Mtb challenge further highlighted the critical importance of Thl cytokines in mediating protective immunity against $\mathrm{TB}$ infection. ${ }^{16}$ In humans, individuals carrying genotypes (that is, IFNGR1, IL-12B, IL12RB1) with impaired Th1 immune response are associated with increased susceptibility to mycobacterial diseases. ${ }^{17-19}$

\footnotetext{
${ }^{1}$ Department of Microbiology, Key Laboratory for Tropical Diseases Control of the Ministry of Education, Zhongshan School of Medicine, Sun Yat-sen University, Guangzhou, Guangdong 510080, China; 'Guangdong Key Laboratory of Emerging Infectious Diseases, Shenzhen Third People's Hospital, Guangdong Medical University, Shenzhen, Guangdong 518112, China and ${ }^{3}$ Department of Pathogen Biology, Shenzhen University School of Medicine, Shenzhen, Guangdong 518060, China

Correspondence: Dr G Zeng, PhD, Dr G Zhang, PhD or Dr X Chen, PhD, Guangdong Key Laboratory of Emerging Infectious Diseases, Shenzhen Third People's Hospital, Guangdong Medical University, No. 29 Bulan Road, Longgang District, Shenzhen, Guangdong 518112, China.

E-mail: zenggch@mail.sysu.edu.cn, szdsyy@aliyun.com or chenxinchun@szu.edu.cn

Received: 26 May 2017; Revised: 15 September 2017; Accepted: 19 September 2017
} 


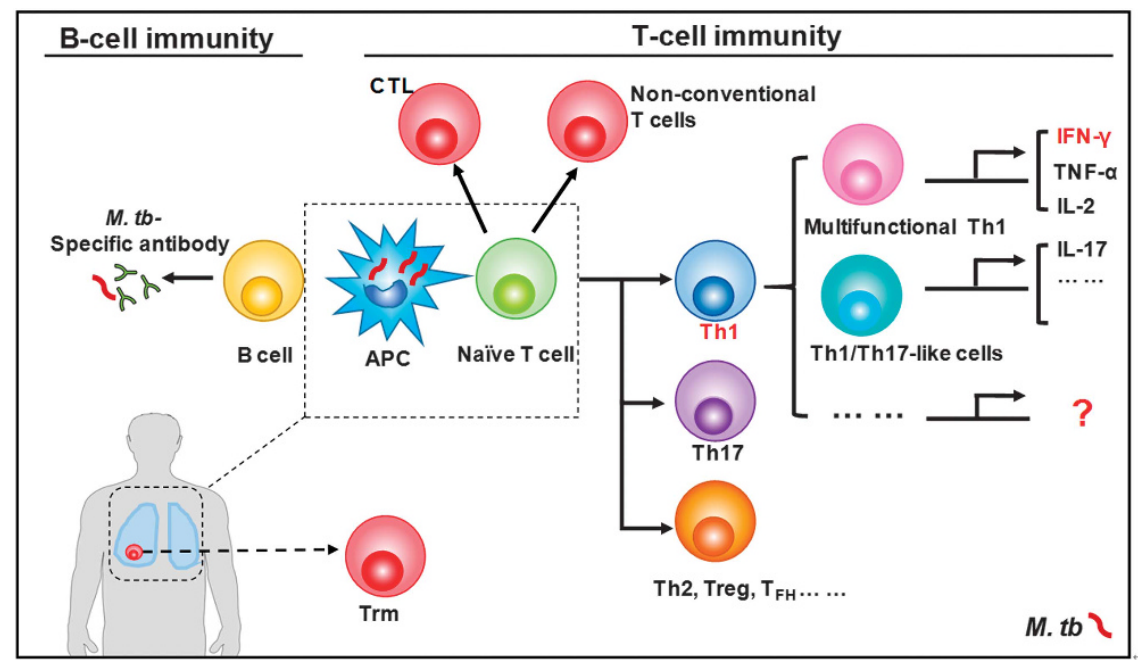

Figure 1 Protective immunity against Mtb infection. Upon exposure to Mtb, antigen-presenting cells (APC) in the lungs process bacterial antigens and present them to naive T cells, which become activated shortly thereafter. Both B-cell immunity and T-cell immunity are essential for the successful clearance of bacteria. B-cell-mediated immune responses are represented by the activation of B cells and subsequently the elevated production of Mtb-specific antibodies. T-cell immunity can be mediated by a variety of T cells, including CTLs, non-conventional T cells, Th1, Th17, Th2, Treg, $\mathrm{T}_{\mathrm{FH}}$ and other cells. Among them, cells involved in Th1 responses against Mtb are the best characterized, and they are composed of multifunctional Th1 cells that secrete IFN- $\gamma$, TNF- $\alpha$ and IL-2, Th1/Th17-like cells that secrete IL-17 and other cytokines, and other uncharacterized T cells. Recent studies also emphasize the protective role of Trm in TB. Trm cells are a subset of $T$ cells that permanently reside in lung tissue to respond rapidly to re-exposure to cognate antigens.

Nevertheless, it is noteworthy that IFN- $\gamma$ is essential, but not sufficient, for bacterial control after Mtb infection, as mice with intact IFN- $\gamma$ but which were deficient in TNF- $\alpha$, GM-CSF, IL-1 or IL-6 all succumbed to Mtb infection. In other words, these results suggest that additional cellular responses are involved in protective immunity against $\mathrm{TB}$. In contrast to its protective role, recent evidence showed that Th1-mediated IFN- $\gamma$ response inhibited inflammation during TB and was involved in TB immunopathology. ${ }^{15,20,21}$

Due to the discrepant efficacy of Mycobacterium bovis Bacille Calmette-Guerin (BCG) in preventing reactivation or reinfection of Mtb in adults, at least 15 vaccine candidates have entered clinical trials within the last decades. ${ }^{22}$ Although they are excellent in induction of Mtb antigen-specific IFN- $\gamma$ producing Th1 immune responses after systematic administration, none were proven to be more effective at preventing $\mathrm{TB}$ than BCG. One of the most promising vaccine candidates, a modified Vaccinia Ankara vector expressing Mtb antigen 85A (MVA85A), was able to elicit powerful Th1 responses, but no significant protection beyond BCG alone was observed. ${ }^{23}$

While these $\mathrm{TB}$ vaccine candidates varied in antigen selection or strategies (such as vaccination routes), the fact that they all failed to elicit efficient protection against TB argues against the consensus that Th1 cytokines are useful surrogate markers of protective immunity against TB in humans. Clearly, fine delineation of the surrogate markers of protective immunity against TB, alternative to the current Th1 cytokine IFN $-\gamma$, is fundamental for the development of a $\mathrm{TB}$ vaccine. In this review, we discuss potential questions that need to be addressed to envision useful signatures for protective immunity against TB.

\section{DO PERIPHERAL TH1 RESPONSES REPRESENT TRUE PROTECTIVE IMMUNITY IN THE LUNGS?}

The acquisition of T-cell immunity in the lung upon Mtb infection is exceedingly slow after aerosol challenge. Generally, Mtb enters deeper alveoli in the form of minute alveoli, where they are engulfed by alveolar macrophages. After $\sim 9$ days, the bacteria can be transported into draining lymph nodes, where dendritic cells (DCs) present Mtb antigens to $\mathrm{T}$ lymphocytes. ${ }^{24,25}$ Once $\mathrm{T}$ cells are activated in the lymph nodes, they differentiate into effector cells, which can migrate into the lungs. ${ }^{26}$ Effective T-cell-mediated protection is initiated by day 14 post infection in mice. ${ }^{27}$ In humans, T-cell responses were detected after 42 days post exposure. ${ }^{28,29}$ Therefore, it has been postulated that although systematic immunization elicits peripheral Th1 cell responses, delayed immune responses in the lung provide an excellent timeframe for Mtb growth and persistent infection establishment, rendering adaptive immunity unable to successfully eradicate the bacterial infection. In support of this concept, previous studies have indicated that it is not the magnitude of the Th1 response, but the rate of Th1 cell migration into the lung, that determines protective immunity against $\mathrm{TB}^{30-32}$ In other words, earlier arrival of effector Th1 cells (measured as antigen-specific IFN- $\gamma$-producing CD4 T cells) to the site of infection correlated with earlier restriction of mycobacterial growth in the lung of BCG-vaccinated mice. ${ }^{33}$ Consequently, the Th1 responses in peripheral blood, as assayed by the frequency of Th1 cells or the ability to produce INF- $\gamma$ after Mtb antigen stimulation ex vivo, cannot faithfully reflect the immune responses that occur in the lung or at least cannot accurately reflect the rate of Th1 cell migration. 
Given that the lung is the place where infected bacillus is cleared, it has been increasingly recognized that tissue resident memory $\mathrm{T}$ cells (Trm) in the lung are critical for protection against $\mathrm{TB}^{34-36}$ in addition to the $\mathrm{T}$ cells that have migrated into the lung. Trm cells, expressing mainly the surface markers of CD69 and CD103, have been recognized as the third subset of memory $\mathrm{T}$ cells with distinct properties of phenotype, migration, retention, and functional maintenance that are different from peripheral T cells. Unlike central memory $\mathrm{T}$ cells, which migrate to lymphoid organs in response to L-selectin ligands, and effector memory $\mathrm{T}$ cells, which recirculate between blood and peripheral tissues, Trm cells permanently reside in non-lymphoid tissues and therefore cannot be detected in peripheral blood. ${ }^{37}$ They are clonally expanded memory $\mathrm{T}$ cells that have the ability to respond rapidly to re-exposure to cognate antigens. ${ }^{38}$

Although early findings did not characterize the exact role of Trm in protective immunity against $\mathrm{TB}$ using the surface markers of CD69 and CD103, it has been observed that the inhibition of mycobacterial growth coincides with the presence of activated CD4 $\mathrm{T}$ cells detected in the lung. ${ }^{39}$ In addition, it has been found that memory CD8 $\mathrm{T}$ cells in the airway can confer protection in the absence of peripheral T-cell recruitment. ${ }^{34}$ By using fingolimod, a ligand for sphingosine-1 phosphate receptors, to prevent CD4 T-cell egress from the existing lymph node, it was further demonstrated that memory $\mathrm{T}$ cells residing in the lung were sufficient for earlier BCG-driven control of an intranasal BCG challenge and that they did not require help from $\mathrm{T}$ cells recruited from the lymph node. ${ }^{35}$ Notably, the protection did not correlate with the magnitude of either IFN- $\gamma$ - or IFN- $\gamma /$ TNF- $\alpha /$ IL-2-producing Th1 cell responses, arguing against the concept that these typical Th1 cytokines, even those produced in the lung, act as sufficient surrogates for protective immunity against TB. The protective role of lung Trm was recently established by adoptive transfer of Trm collected from mice that received mucosal BCG vaccination. ${ }^{36}$ Phenotypic analysis showed that these Mtb antigen-specific CD8 Trm (CD8+CD103+CD69+) cells displayed prototypical Trm features with significantly higher levels of IFNG, TNFA and CXCR6 compared to CD8 effector memory counterparts. In contrast, CD4 Trm cells, defined as CD4 $+\mathrm{CD} 103+\mathrm{CD} 69+$ cells, comprise a mixture of regulatory and effector T cells, specifically T-bet- and FoxP3-expressing T-cell subsets, with enhanced IL-10 transcripts. These findings suggest that lung CD4 T cells confer diverse functions well beyond the classical Th1 responses that were previously considered to be correlated with protection; therefore, CD4 T-cell activities cannot be reflected by typical peripheral Th1 cytokines. ${ }^{36}$

However, most of the current studies showing the importance of Trm in Mtb infection are correlational studies. There is a notable lack of direct evidence demonstrating a causal relationship between the immune characteristics of Trm and the protective roles of Trm against TB. Additionally, we cannot rule out the possibility that Trm may play a pathological role during TB infection. Furthermore, CD8+Trm and CD4+Trm may display distinct immune features during microbial infections. Further studies are required to identify accurate molecular markers (not limited to $\mathrm{CD}$ surface makers) for TB-specific CD8+Trm and CD4+Trm. Considering that CD103 was expressed in CD8+ $\mathrm{T}$ cells for maintenance in different types of locations or epithelium, the existence of transcriptional factors or other biomarkers dictating the differentiation and maintenance of Trm in the lung is highly possible. In addition, details on Trm-mediated immunological events and underlying mechanisms during Mtb infection remain to be fully characterized. Specifically, these details are related to antigen-presentation, interactions between immune cells (for example, macrophages (Mథ)-Trm) or with local cells, such as epithelial cells, cross-talk between different signaling pathways, interweaving between different molecular events for the maintenance of Trm in the lungs, and Trm reactivation and deletion during reencounters with TB antigens.

\section{DO CLASSICAL TH1 CYTOKINES REPRESENT THE TRUE FUNCTIONAL SIGNATURE OF PROTECTIVE IMMUNITY?}

As discussed above, classical Th1 cytokines are thought to be inadequate as surrogate protective markers, and new functional signatures for protective immunity against $\mathrm{TB}$ need to be identified. With the emergence of omics science, TB protective biomarkers can be identified through large-scale omics studies, which involve gene expression (transcriptomics), proteins (proteomics) and metabolites (metabolomics) in the blood and lungs. Omics approaches provide a great opportunity to potentially discover new protective biomarkers. Interestingly, a previously unrecognized signature of type I interferon signaling has been identified as a key immune mediator for human TB. ${ }^{40}$ In addition, a 144-transcript signature associated with pulmonary TB has also been identified. ${ }^{41}$

Up until now, a series of cytokines, chemokines and other factors have been shown to be implicated in protective immunity against TB (Table 1 ) in addition to IFN- $\gamma$. Among them, IL-17 represents the best characterized cytokine in the expanding signature panel that illustrates TB protective immunity. IL-17, which is mainly produced by Th17 cells, has been shown to drive Th1 cell responses by overcoming IL-10mediated inhibition after BCG vaccination. ${ }^{84}$ In addition, BCG vaccination expands lung resident IL-17-producing CD4 $\mathrm{T}$ cells that produce chemokines, recruiting IFN- $\boldsymbol{\gamma}$-producing CD4 T cells after Mtb challenge. ${ }^{39}$ Although an early study with Mtb-infected mice shows that Th17 cells had little effect on infection control, ${ }^{85} \mathrm{IL}-17^{-/-}$mice infected with hypervirulent Mtb strain HN878 exhibited increased bacterial burden in lungs compared to WT B6 mice. ${ }^{56}$ The fact that adoptive transfer of ESAT-6-specific Th17 cells partially inhibits Mtb growth supports the involvement of Th17 in TB protection. ${ }^{86}$ Human studies also support a protective role for Th17/IL-17 responses by comparing the responses in $\mathrm{TB}$ patients and healthy individuals. It has been reported that the frequency of Th17 cells in active TB patients is significantly lower than that in healthy controls and LTB individuals, implicating that Th17 cells may contribute to the protection. ${ }^{87}$ Taken together, these results suggest that IL-17 also represents an important mediator 


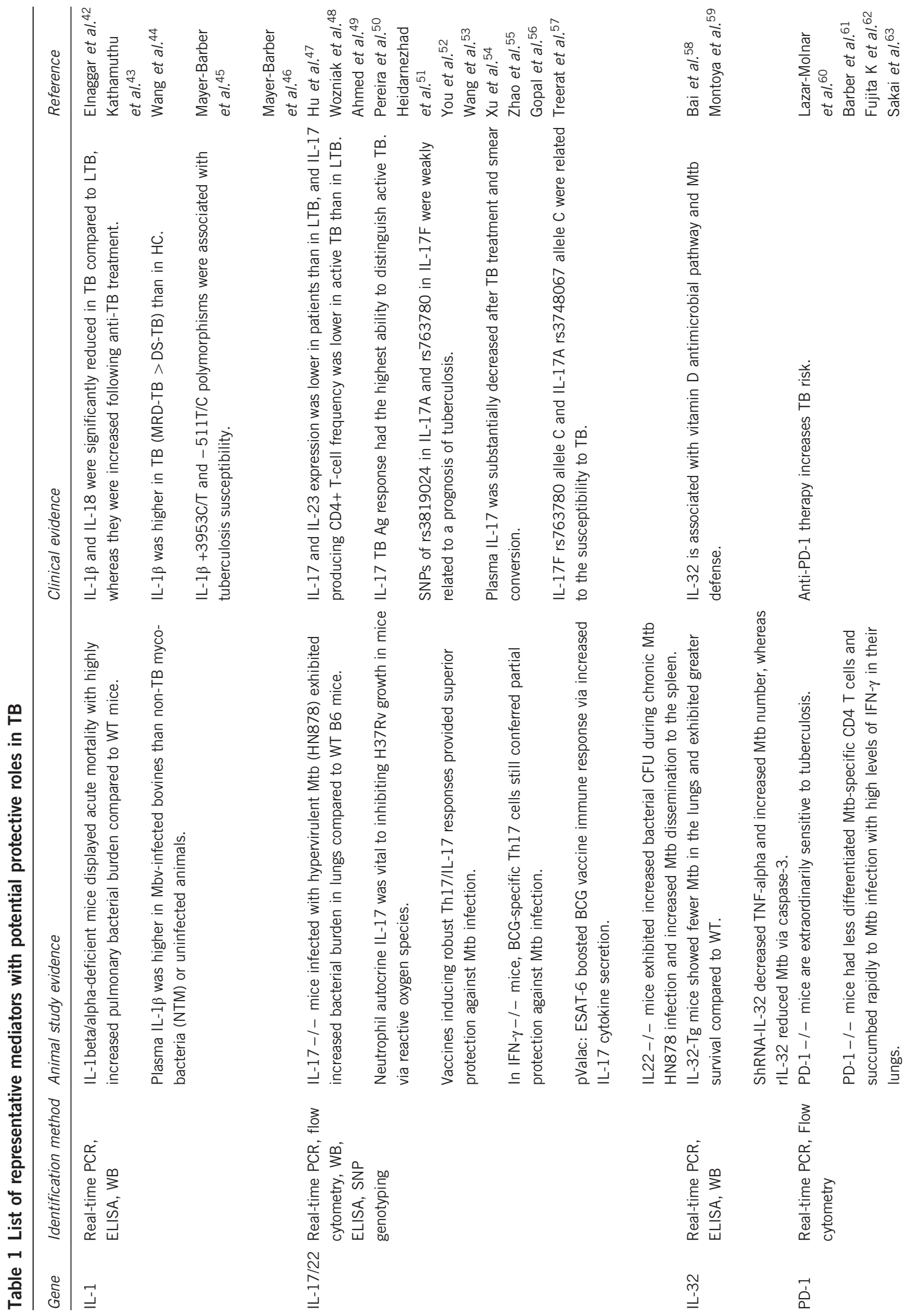




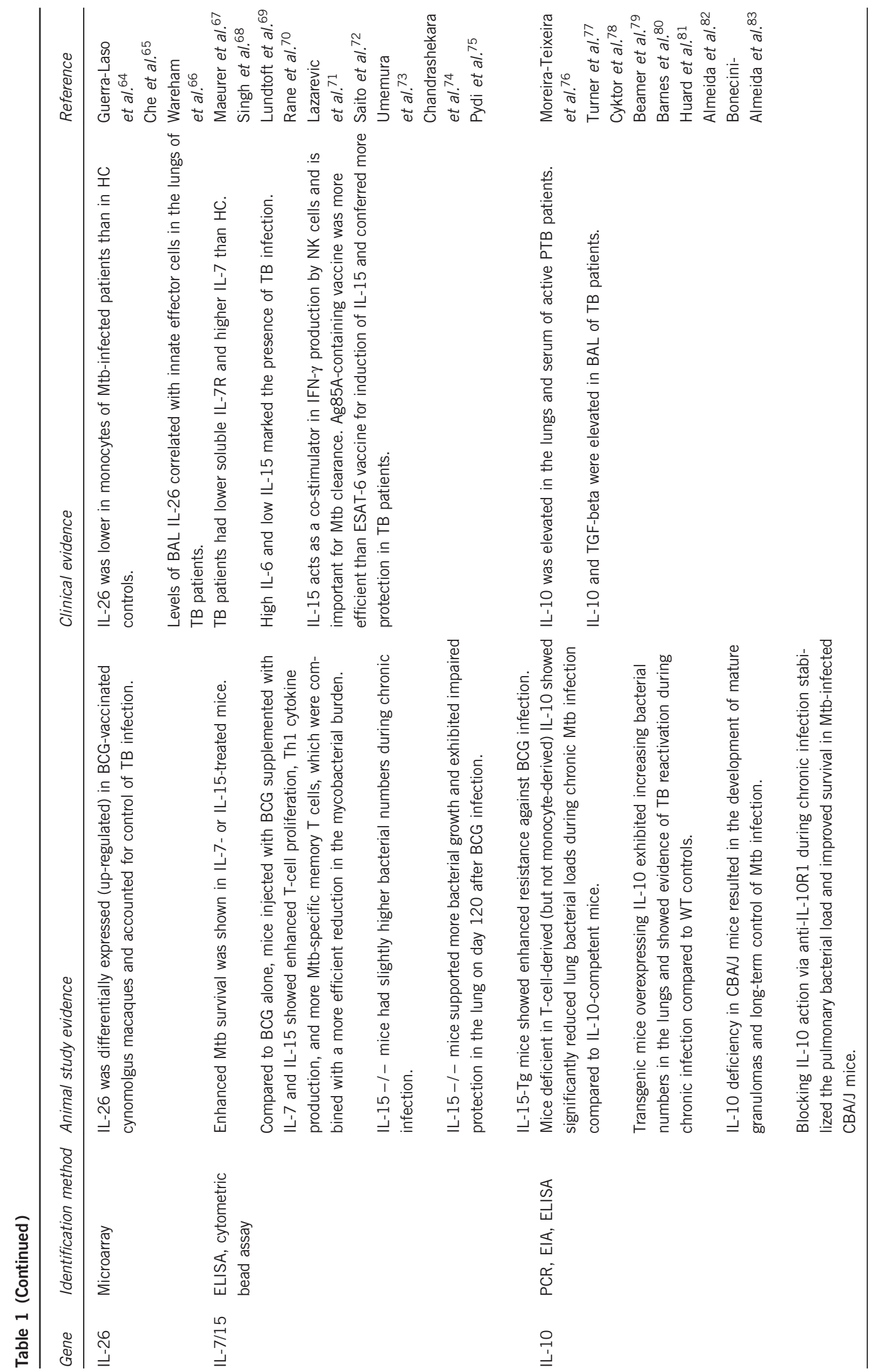


of resistance to $\mathrm{Mtb}$, which could be considered to be a surrogate of protection.

During chronic Mtb infection, immune-mediated tissue damage is frequently more harmful to the host than the pathogen itself. The balance between pro- and anti-inflammatory signals determines $\mathrm{TB}$ development. ${ }^{88} \mathrm{PD}-1$, as a mediator of T-cell exhaustion, has been proven to play a central role in anti-TB immune responses. Inhibition of PD-1 signaling rescues Mtbspecific IFN- $\boldsymbol{\gamma}$-producing $\mathrm{T}$ cells from apoptosis and enhances the specific degranulation of CD8 $\mathrm{T}$ cells for more efficient protection. ${ }^{89,90}$ However, $\mathrm{PD}-1^{-/-}$mice are extraordinarily sensitive to $\mathrm{TB} .{ }^{60}$ Dysregulation of CD4 $\mathrm{T}$ cells promotes rather than controls $\mathrm{TB}$ in the absence of $\mathrm{PD}-1$ signaling. ${ }^{61}$ Therefore, PD-1 deficient mouse studies suggest that PD-1-mediated T-cell exhaustion is essential to controlling excessive immunopathology after Mtb infection. Interestingly, one case report shows that a patient with advanced NSCLC rapidly developed pulmonary TB during anti-PD-1 therapy. ${ }^{62}$ The above studies suggest that immune modulatory molecules, such as PD-1, should also be considered in the design of a successful TB vaccine.

Recent studies have demonstrated that it is feasible to identify novel functional signatures for protective immunity through a comparison of different immune phenotypes of LTBI, active TB, etc. Although approximately $1 / 4$ of the world population is estimated to be infected with Mtb, less than $5-10 \%$ of affected individuals eventually develop active TB diseases. In addition, a perspective cohort study shows that over half of newly identified IGRAs-positive subjects reversed to IGRAs-negative in the second year of follow-up, suggesting that self-clearance of Mtb infection commonly occurs. ${ }^{91}$ Thus, representative immunity in the LTBI population, including transiently IGRAs-positive individuals, potentially represents an immune status that is more effective at containing Mtb infection compared to that in the active TB population. LTBI patients represent a valuable pool for potential biomarker discovery for protective immunity. Following this selective strategy, one study found that IL-32 was a mediator of IFN- $\boldsymbol{\gamma}$-vitamin D-dependent antimicrobial immunity. ${ }^{59}$ In addition, IL-2, MCP-2, IP-10, IFN- $\gamma$, TNFSF14, MIG, and granzyme B have also been identified as associated with LTBI. ${ }^{92}$ A plasma proteomic fingerprint that distinguished active TB from LTBI has also been identified. ${ }^{93}$ However, it is also possible that the immune status in LTBI only represents protective outcomes, not true protective immunity that can successfully control the development of active TB in humans.

The distinct immune profiles between LTBI and active TB infection do not appear to be limited to circulating cytokine/ chemokines. Metabolic products may also be involved in TB development. It was shown that decreased serum 5-oxoproline in $\mathrm{TB}$ patients is associated with pathological damage in the lung. ${ }^{94}$ Metabolic profiles of decreased activity of indoleamine 2,3 dioxygenase 1 (IDO1) and increased phospholipase activity were observed specifically in LTBI but not in active TB patients. $^{95}$ These results suggest that LTBI and active TB display different metabolic profiles. However, we still cannot conclude that these differentiated profiles of cytokine/chemokines and metabolic products are driving immune protection or simply reflecting the outcomes of successful control of Mtb infection. Further animal and human studies should be implemented to investigate the exact roles of the above signatures during Mtb infection.

\section{DO HETEROGENEOUS TH1 CELLS CONFER COMPREHENSIVE T-CELL-MEDIATED PROTECTIVE IMMUNITY?}

While the Mtb-specific Th1 population is highly heterogeneous, it still remains unknown which subpopulation producing IFN- $\gamma$ plays a more critical role against $\mathrm{Mtb}$ infection. First, Mtb contains more than 4000 protein antigens, and there is extensive diversity of immunodominant responses in infected individuals. In addition, gene expression profiles of Mtb are highly dynamic, depending on different immunological/physiological stresses or microenvironments. Mtb could change its gene expression profile from active replication to slow or nonreplication status during infection to fit certain immunological/ physiological stresses or microenvironments, and the resulting protein expression variations might therefore impact the protective capacity of antigen-induced $\mathrm{T}$ cells. ${ }^{96}$ Thus, the immune responses of $\mathrm{T}$ cells derived from PBMC or BAL may not be the ones that are specifically desired for currently existing pathological Mtb antigens. In other words, the T-cell immune responses that are driven by current $\mathrm{TB}$ vaccine candidates may not truly cover protective Mtb antigens.

One study provided evidence that protective CD4 T cells targeting $\mathrm{Mtb}$ cryptic epitopes conferred superior protection to those recognizing immunodominant $\mathrm{Mtb}$ epitopes by eliciting a higher proportion of T-bet $^{\text {int }} \mathrm{KLRG}^{-}$CD4 $\mathrm{T}$ cells. ${ }^{97}$ By comparing the protective efficiency of ESAT- 6 and a truncated ESAT-6 molecule ( $\Delta 15$ ESAT-6) that lacks the immunodominant ESAT-6 epitope, it was shown that the most efficient protection against Mtb aerosol challenge is mediated by the subdominant T-cell repertoire primed by $\Delta 15$ ESAT- $6 .{ }^{98}$ In this regard, definition of true protective or pathological Mtb antigens and/or epitopes is certainly critical for an improved understanding of TB immunobiology and for the development of vaccines and immunodiagnostics.

Second, Th1 cells can gain the capacity to secrete several cytokines, and these 'multifunctional' Th1 cells mainly produce IFN- $\gamma$, TNF- $\alpha$, and IL-2 (Figure 1). ${ }^{99}$ However, the exact roles of multifunctional Th1 cells in TB diseases remain controversial. Several studies show higher frequencies of IFN- $\gamma^{+}$TNF- $\alpha^{+}$IL- $2^{+}$ Mtb-specific CD4 T cells in LTBI compared to TB patients. ${ }^{100-103}$ However, other studies have found that frequencies of IFN- $\gamma$ ${ }^{+}$TNF- $\alpha^{+}$IL- ${ }^{+}$CD4 $\mathrm{T}$ cells increased in active TB patients and normalized after anti-TB treatment. ${ }^{104-106}$ In addition, there is evidence indicating that most multifunctional $\mathrm{T}$ cells produce cytokines in a sequential fashion. For example, it was proven that multifunctional Th1-skewed cytokine responses (IFN- $\gamma$, IL-2 andTNF- $\alpha$ ) are initiated asynchronously and that TNF- $\alpha$ production generally precedes IFN- $\gamma$ and IL-2 synthesis through time-dependent, single-cell analysis of primary human T cells. ${ }^{107}$

Third, the heterogeneity of Th1 cells also comes from a new subset of Th1/Th17-like cells coexpressing T-bet and ROR $\gamma$ t, 
which exhibit Th1-like and Th17-like characteristics. ${ }^{108}$ Although Th1/Th17-like cells were proven to be pathogenic in the gut of patients with Crohn's disease, ${ }^{15}$ the exact roles of Th1/Th17-like cells in TB patients are unclear. One study demonstrated that higher frequencies of Th1/Th17-like cells, the main source of IL-17, are highly correlated with disease severity in TB patients. ${ }^{109}$ Studies of Mtb-specific memory $\mathrm{T}$ cells have revealed that $\mathrm{CCR} 6{ }^{+} \mathrm{CXCR} 3^{+} \mathrm{CD} 4^{+} \mathrm{T}$ cells, displaying hallmarks of both Th1 and Th17 transcriptional programs, are significantly increased in LTBI donors compared to healthy controls. ${ }^{110}$ Furthermore, isolated CXCR3 ${ }^{+} \mathrm{CCR}^{+}$ $\mathrm{CD}^{+} \mathrm{T}$ cells from LTBI individuals exhibit higher proliferative ability upon stimulation with Mtb antigens. ${ }^{111}$

Finally, deep sequencing T-cell receptor (TCR) of $\mathrm{T}$ cells stimulated by Mtb antigens demonstrates that human memory CD4+ T-cell clones are highly heterogenic in function, and different patterns of clonotype sharing among three Mtbspecific CCR6+ T-cell subsets were observed. ${ }^{112}$ Thus, Mtbspecific Th cells are comprised of not only clones polarized toward a single fate but also clones whose progenies have acquired multiple fates. However, the exact molecular mechanisms by which the heterogeneities of Mtb-specific Th cells are shaped and how these heterogeneities dictate the pathological or protective outcomes of Mtb infection remain to be elucidated.

Thus, the current Th1 cell responses defined by limited known antigen specificity and classical cytokines profiles cannot represent comprehensive protective immunity due to the heterogeneity of Th1 cells. It is reasonable to hypothesize that only some TB-specific Th1 cells or T cells are truly and fully protective and that only these $\mathrm{T}$ cells should serve as targets for new TB vaccines. To overcome this limit, a better solution should analyze not only Th1 cells but also other $\mathrm{T}$ cells, at single-cell level, to clearly delineate TCR specificity and characterize each TB-specific T-cell in Mtb infection.

\section{DO HUMORAL IMMUNE RESPONSES PROVIDE PROTECTION AGAINST MTB INFECTION?}

Unlike well-established T-cell-mediated immune responses, the role of humoral immune responses remains largely controversial. Humoral immunity has long been believed to play little or no function against $\mathrm{Mtb}$, an intracellular pathogen that is traditionally considered to be out of the reach of antibodies. However, this view has been progressively changing. Recently, an antibody profiling study on Mtb-specific humoral responses revealed that LTBI individuals have unique antibody Fc functional profiles, selective binding to FcyRIII, and distinct antibody glycosylation patterns that clearly distinguish them from active TB patients. ${ }^{113}$ Most notably, the PPD-specific antibody purified from the sera of LTBI, but not active TB, could inhibit Mtb growth in macrophages. ${ }^{113}$ The potential involvement of humoral immunity in Mtb defense is further supported by evidence that passive transfer of Mtb-specific monoclonal antibodies, ${ }^{114-117}$ intravenous immunoglobulins, ${ }^{118}$ and homologous immune sera ${ }^{119,120}$ is efficient at providing protection against $\mathrm{Mtb}$ infection in murine models. On the other hand, another study has shown that the blocking activity of antibodies against $\mathrm{Mtb}$ is dependent on antibody isotype and independent of $\mathrm{Fc}$ alpha receptor expression on host cells. ${ }^{121}$ Furthermore, antibodies from uninfected healthcare workers who had no prior evidence of latent TB infection, a subset of 'restrictors', show moderate protection against $\mathrm{Mtb}$ in aerosol-challenged mice, but this protection is absent with antibodies derived from Mtb active patients. ${ }^{122}$

Taken together, the exact protective role and underlying mechanisms of antibodies against TB need to further defined, as antibody-mediated potential protection might be an important contributor to the true functional signature of protective immunity. More importantly, emerging evidence suggesting the protective effects of antibodies implicates that our current view of TB immunobiology is still in its infancy stage. More protective paradigms are still hidden and waiting to be identified.

\section{CONCLUDING REMARKS}

The lack of useful surrogate markers for protective immunity hinders $\mathrm{TB}$ vaccine development. Although antigen-specific Th1 cytokines have been currently used to determine the protective efficacy of $\mathrm{TB}$ vaccines, vaccine candidates with a strong ability to induce Th1 cytokine production did not confer full protection against $\mathrm{TB}$ in humans. Future studies using integrated omics and single-cell sequencing to elucidate the comprehensive, delicate, precise $\mathrm{T}$-cell responses in the lung will eventually discover true protective functional signatures. The recent findings on the protective role of antibodies suggest that antibodies might be an important contributor to the true functional signature of protective immunity.

\section{CONFLICT OF INTEREST}

The authors declare no conflict of interest.

\section{ACKNOWLEDGEMENTS}

This study was supported by Thirteenth-Fifth Mega-Scientific Projects (2017ZX10103004); National Natural Science Foundation of China (81501714, 81525016, 81471913); National Key R\&D Program of China (2016YFE0106900); Natural Science Foundation of Guangdong (2014A030313789); Shenzhen Scientific and Technological Project (JCYJ20170307095003051, JCYJ20170412151620658 and JSGG20140701164 558078); and Sanming Project of Medicine in Shenzhen (GCZX2015043015340 574, ZDSYS201504301534057).

1 Lefford MJ. Transfer of adoptive immunity to tuberculosis in mice. Infect Immunity 1975; 11: 1174-1181.

2 Orme IM, Collins FM. Protection against Mycobacterium tuberculosis infection by adoptive immunotherapy. Requirement for $\mathrm{T}$ celldeficient recipients. J Exp Med 1983; 158: 74-83.

3 Cooper AM. Cell-mediated immune responses in tuberculosis. Annu Rev Immunol 2009; 27: 393-422.

4 Orme IM. The kinetics of emergence and loss of mediator $T$ lymphocytes acquired in response to infection with Mycobacterium tuberculosis. J Immunol 1987; 138: 293-298.

5 Mogues T, Goodrich ME, Ryan L, LaCourse R, North RJ. The relative importance of $T$ cell subsets in immunity and immunopathology of airborne Mycobacterium tuberculosis infection in mice. J Exp Med 2001; 193: 271-280.

6 Yao S, Huang D, Chen CY, Halliday L, Wang RC, Chen ZW. CD4+ $T$ cells contain early extrapulmonary tuberculosis (TB) dissemination and rapid TB progression and sustain multieffector functions of CD8+ 
T and CD3- lymphocytes: mechanisms of CD4+ T cell immunity. J Immunol 2014; 192: 2120-2132.

7 Havlir DV, Barnes PF. Tuberculosis in patients with human immunodeficiency virus infection. N Engl J Med 1999; 340: 367-373.

8 Getahun H, Matteelli A, Chaisson RE, Raviglione M. Latent Mycobacterium tuberculosis infection. N Engl J Med 2015; 372 2127-2135.

9 Cooper AM, Dalton DK, Stewart TA, Griffin JP, Russell DG, Orme IM. Disseminated tuberculosis in interferon gamma gene-disrupted mice. J Exp Med 1993; 178: 2243-2247.

10 Cooper AM, Magram J, Ferrante J, Orme IM. Interleukin 12 (IL-12) is crucial to the development of protective immunity in mice intravenously infected with mycobacterium tuberculosis. J Exp Med 1997; 186: 39-45.

11 Flynn JL, Chan J, Triebold KJ, Dalton DK, Stewart TA, Bloom BR. An essential role for interferon gamma in resistance to Mycobacterium tuberculosis infection. J Exp Med 1993; 178: 2249-2254.

12 MacMicking JD, North RJ, LaCourse R, Mudgett JS, Shah SK, Nathan $\mathrm{CF}$. Identification of nitric oxide synthase as a protective locus against tuberculosis. Proc Natl Acad Sci USA 1997; 94: 5243-5248.

13 Cooper AM, Segal BH, Frank AA, Holland SM, Orme IM. Transient loss of resistance to pulmonary tuberculosis in p47(phox-/-) mice. Infect Immunity 2000; 68: 1231-1234.

14 Scanga CA, Mohan VP, Tanaka K, Alland D, Flynn JL, Chan J. The inducible nitric oxide synthase locus confers protection against aerogenic challenge of both clinical and laboratory strains of Mycobacterium tuberculosis in mice. Infect Immunity 2001; 69: 7711-7717.

15 Lyadova IV, Panteleev AV. Th1 and Th17 cells in tuberculosis: protection, pathology, and biomarkers. Mediat Inflamm 2015; 2015: 854507.

16 Du G, Chen CY, Shen Y, Qiu L, Huang D, Wang R et al. TCR repertoire, clonal dominance, and pulmonary trafficking of mycobacterium-specific CD4+ and CD8+ T effector cells in immunity against tuberculosis. J Immunol 2010; 185: 3940-3947.

17 Newport MJ, Huxley CM, Huston S, Hawrylowicz CM, Oostra BA Williamson $\mathrm{R}$ et al. A mutation in the interferon-gamma-receptor gene and susceptibility to mycobacterial infection. N Engl J Med 1996; 335: 1941-1949.

18 Elloumi-Zghal H, Barbouche MR, Chemli J, Bejaoui M, Harbi A Snoussi $\mathrm{N}$ et al. Clinical and genetic heterogeneity of inherited autosomal recessive susceptibility to disseminated Mycobacterium bovis bacille calmette-guerin infection. J Infect Dis 2002; 185: 1468-1475.

19 Sakai T, Matsuoka M, Aoki M, Nosaka K, Mitsuya H. Missense mutation of the interleukin-12 receptor betal chain-encoding gene is associated with impaired immunity against Mycobacterium avium complex infection. Blood 2001; 97: 2688-2694.

20 Sahiratmadja E, Alisjahbana B, Buccheri S, Di Liberto D, de Boer T, Adnan I et al. Plasma granulysin levels and cellular interferon-gamma production correlate with curative host responses in tuberculosis, while plasma interferon-gamma levels correlate with tuberculosis disease activity in adults. Tuberculosis 2007; 87: 312-321.

21 Nandi B, Behar SM. Regulation of neutrophils by interferon-gamma limits lung inflammation during tuberculosis infection. J Exp Med 2011; 208: 2251-2262.

22 Andersen P, Woodworth JS. Tuberculosis vaccines-rethinking the current paradigm. Trends Immunol 2014; 35: 387-395.

23 Tameris MD, Hatherill M, Landry BS, Scriba TJ, Snowden MA, Lockhart $\mathrm{S}$ et al. Safety and efficacy of MVA85A, a new tuberculosis vaccine, in infants previously vaccinated with BCG: a randomised, placebo-controlled phase 2b trial. Lancet 2013; 381: 1021-1028.

24 Orme IM, Robinson RT, Cooper AM. The balance between protective and pathogenic immune responses in the TB-infected lung. Nat Immunol 2015; 16: 57-63.

25 Cooper AM. T cells in mycobacterial infection and disease. Curr Opin Immunol 2009; 21: 378-384.

26 Reiley WW, Calayag MD, Wittmer ST, Huntington JL, Pearl JE, Fountain JJ et al. ESAT-6-specific CD4 T cell responses to aerosol Mycobacterium tuberculosis infection are initiated in the mediastinal lymph nodes. Proc Natl Acad Sci USA 2008; 105: 10961-10966.

27 Wolf AJ, Linas B, Trevejo-Nunez GJ, Kincaid E, Tamura T, Takatsu K et al. Mycobacterium tuberculosis infects dendritic cells with high frequency and impairs their function in vivo. J Immunol 2007; 179: 2509-2519.

28 Poulsen A. Some clinical features of tuberculosis. 1. Incubation period. Acta tuberculosea Scandinavica 1950; 24: 311-346.

29 Wallgren A. The time-table of tuberculosis. Tubercle 1948; 29. 245-251.

30 Shafiani S, Tucker-Heard G, Kariyone A, Takatsu K, Urdahl KB. Pathogen-specific regulatory $T$ cells delay the arrival of effector $T$ cells in the lung during early tuberculosis. J Exp Med 2010; 207: 1409-1420.

31 Tchilian EZ, Ronan EO, de Lara C, Lee LN, Franken KL, Vordermeier $\mathrm{MH}$ et al. Simultaneous immunization against tuberculosis. PLOS ONE 2011; 6: e27477.

32 Beverley PC, Sridhar S, Lalvani A, Tchilian EZ. Harnessing local and systemic immunity for vaccines against tuberculosis. Mucosal immunology 2014; 7: 20-26.

33 Jung YJ, Ryan L, LaCourse R, North RJ. Properties and protective value of the secondary versus primary $T$ helper type 1 response to airborne Mycobacterium tuberculosis infection in mice. J Exp Med 2005; 201: 1915-1924.

34 Jeyanathan M, Mu J, McCormick S, Damjanovic D, Small CL, Shaler CR et al. Murine airway luminal antituberculosis memory CD8 T cells by mucosal immunization are maintained via antigendriven in situ proliferation, independent of peripheral $\mathrm{T}$ cell recruitment. Am J Respir Crit Care Med 2010; 181: 862-872.

35 Connor LM, Harvie MC, Rich FJ, Quinn KM, Brinkmann V, Le Gros G et al. A key role for lung-resident memory lymphocytes in protective immune responses after BCG vaccination. Eur J Immunol 2010; 40: 2482-2492.

36 Perdomo C, Zedler U, Kuhl AA, Lozza L, Saikali P, Sander LE et al. Mucosal BCG Vaccination Induces Protective Lung-Resident Memory $T$ Cell Populations against Tuberculosis. mBio 2016; 7: pii: e01686-16.

37 Gebhardt T, Wakim LM, Eidsmo L, Reading PC, Heath WR, Carbone FR. Memory T cells in nonlymphoid tissue that provide enhanced local immunity during infection with herpes simplex virus. Nat Immunol 2009; 10: 524-530.

38 Clark RA. Resident memory T cells in human health and disease. Science translational medicine 2015; 7: 269rv261.

39 Khader SA, Bell GK, Pearl JE, Fountain JJ, Rangel-Moreno J, Cilley GE et al. IL-23 and IL-17 in the establishment of protective pulmonary CD4+ $\mathrm{T}$ cell responses after vaccination and during Mycobacterium tuberculosis challenge. Nat Immunol 2007; 8: 369-377.

40 Berry MP, Graham CM, McNab FW, Xu Z, Bloch SA, Oni T et al. An interferon-inducible neutrophil-driven blood transcriptional signature in human tuberculosis. Nature 2010; 466: 973-977.

41 Bloom Cl, Graham CM, Berry MP, Rozakeas F, Redford PS, Wang Y et al. Transcriptional blood signatures distinguish pulmonary tuberculosis, pulmonary sarcoidosis, pneumonias and lung cancers. PLoS ONE 2013; 8: e70630.

42 Elnaggar MM, Abdellrazeq GS, Elsisy A, Mahmoud AH, Shyboub A Sester $\mathrm{M}$ et al. Evaluation of antigen specific interleukin-1beta as a biomarker to detect cattle infected with Mycobacterium bovis. Tuberculosis 2017; 105: 53-59.

43 Kathamuthu GR, Moideen K, Bhaskaran D, Sekar G, Sridhar R, Vidyajayanthi $\mathrm{B}$ et al. Reduced systemic and mycobacterial antigenstimulated concentrations of IL-1beta and IL-18 in tuberculous lymphadenitis. Cytokine 2017; 90: 66-72.

44 Wang Y, Hu C, Wang Z, Kong H, Xie W, Wang H. Serum IL-1beta and IL-18 correlate with ESR and CRP in multidrug-resistant tuberculosis patients. J Med Res 2015; 29: 426-428.

45 Mayer-Barber KD, Andrade BB, Barber DL, Hieny S, Feng CG, Caspar P et al. Innate and adaptive interferons suppress IL-1alpha and IL-1beta production by distinct pulmonary myeloid subsets during Mycobacterium tuberculosis infection. Immunity 2011; 35: 1023-1034.

46 Mayer-Barber KD, Barber DL, Shenderov K, White SD, Wilson MS, Cheever A et al. Caspase-1 independent IL-1 beta production is critical for host resistance to mycobacterium tuberculosis and does not require TLR signaling in vivo. J Immunol 2010; 184: 3326-3330.

47 Hu S, He W, Du X, Yang J, Wen Q, Zhong XP et al. IL-17 production of neutrophils enhances antibacteria ability but promotes arthritis development during mycobacterium tuberculosis infection. EBioMedicine 2017; 23: 88-99. 
48 Wozniak TM, Saunders BM, Ryan AA, Britton WJ. Mycobacterium bovis BCG-specific Th17 cells confer partial protection against Mycobacterium tuberculosis infection in the absence of gamma interferon. Infect Immunity 2010; 78: 4187-4194.

49 Ahmed M, Smith DM, Hamouda T, Rangel-Moreno J, Fattom A, Khader SA. A novel nanoemulsion vaccine induces mucosal Interleukin-17 responses and confers protection upon Mycobacterium tuberculosis challenge in mice. Vaccine 2017; 35: 4983-4989.

50 Pereira VB, da Cunha VP, Preisser TM, Souza BM, Turk MZ, De Castro $\mathrm{CP}$ et al. Lactococcus lactis carrying a DNA vaccine coding for the ESAT- 6 antigen increases IL-17 cytokine secretion and boosts the BCG vaccine immune response. J App/ Microbiol 2017; 122: $1657-1662$.

51 Heidarnezhad F, Asnaashari A, Rezaee SA, Ghezelsofla R, Ghazvini K, Valizadeh $\mathrm{N}$ et al. Evaluation of Interleukin17and Interleukin 23 expression in patients with active and latent tuberculosis infection. Iran J Basic Med Sci 2016; 19: 844-850.

52 You E, Kim MH, Lee WI, Kang SY. Evaluation of IL-2, IL-10, IL-17 and IP-10 as potent discriminative markers for active tuberculosis among pulmonary tuberculosis suspects. Tuberculosis 2016; 99: $100-108$

53 Wang M, Xu G, Lu L, Xu K, Chen Y, Pan H et al. Genetic polymorphisms of IL-17A, IL-17F, TLR4 and miR-146a in association with the risk of pulmonary tuberculosis. Sci Rep 2016; 6: 28586.

54 Xu L, Cui G, Jia H, Zhu Y, Ding Y, Chen J et al. Decreased IL-17 during treatment of sputum smear-positive pulmonary tuberculosis due to increased regulatory T cells and IL-10. J Trans/ Med 2016; 14: 179.

55 Zhao J, Wen C, Li M. Association analysis of interleukin-17 gene polymorphisms with the risk susceptibility to tuberculosis. Lung 2016; 194: 459-467.

56 Gopal R, Monin L, Slight S, Uche U, Blanchard E, Fallert Junecko BA et al. Unexpected role for IL-17 in protective immunity against hypervirulent Mycobacterium tuberculosis HN878 infection. PLoS Pathog 2014; 10: e1004099.

57 Treerat $P$, Prince O, Cruz-Lagunas A, Munoz-Torrico M, SalazarLezama MA, Selman M et al. Novel role for IL-22 in protection during chronic Mycobacterium tuberculosis HN878 infection. Mucosal Immunol 2017; 10: 1069-1081.

58 Bai X, Shang S, Henao-Tamayo M, Basaraba RJ, Ovrutsky AR, Matsuda JL et al. Human IL-32 expression protects mice against a hypervirulent strain of Mycobacterium tuberculosis. Proc Natl Acad Sci USA 2015; 112: 5111-5116.

59 Montoya D, Inkeles MS, Liu PT, Realegeno S, Teles RM, Vaidya P et al. IL-32 is a molecular marker of a host defense network in human tuberculosis. Sci Transl Med 2014; 6: 250ra114.

60 Lazar-Molnar E, Chen B, Sweeney KA, Wang EJ, Liu W, Lin J et al. Programmed death-1 (PD-1)-deficient mice are extraordinarily sensitive to tuberculosis. Proc Natl Acad Sci USA 2010; 107: 13402-13407.

61 Barber DL, Mayer-Barber KD, Feng CG, Sharpe AH, Sher A. CD4 $\mathrm{T}$ cells promote rather than control tuberculosis in the absence of PD-1-mediated inhibition. J Immunol 2011; 186: 1598-1607.

62 Fujita K, Terashima T, Mio T. Anti-PD1 antibody treatment and the development of acute pulmonary tuberculosis. J Thorac Oncol 2016; 11: 2238-2240.

63 Sakai S, Kauffman KD, Sallin MA, Sharpe AH, Young HA, Ganusov VV et al. CD4 T cell-derived ifn-gamma plays a minimal role in control of pulmonary mycobacterium tuberculosis infection and must be actively repressed by PD-1 to prevent lethal disease. PLoS Pathog 2016; 12: e1005667.

64 Guerra-Laso JM, Raposo-Garcia S, Garcia-Garcia S, Diez-Tascon C, Rivero-Lezcano OM. Microarray analysis of Mycobacterium tuberculosis-infected monocytes reveals IL26 as a new candidate gene for tuberculosis susceptibility. Immunology 2015; 144: 291-301.

65 Che KF, Tengvall S, Levanen B, Silverpil E, Smith ME, Awad M et al. Interleukin-26 in antibacterial host defense of human lungs. Effects on neutrophil mobilization. Am J Respir Crit Care Med 2014; 190: 1022-1031.
66 Wareham AS, Tree JA, Marsh PD, Butcher PD, Dennis M, Sharpe SA. Evidence for a role for interleukin-17, Th17 cells and iron homeostasis in protective immunity against tuberculosis in cynomolgus macaques. PLoS One 2014; 9: e88149.

67 Maeurer MJ, Trinder P, Hommel G, Walter W, Freitag K, Atkins D et al. Interleukin-7 or interleukin-15 enhances survival of Mycobacterium tuberculosis-infected mice. Infect Immunity 2000; 68: 2962-2970.

68 Singh V, Gowthaman U, Jain S, Parihar P, Banskar S, Gupta P et al. Coadministration of interleukins 7 and 15 with bacille CalmetteGuerin mounts enduring T cell memory response against Mycobacterium tuberculosis. J Infect Dis 2010; 202: 480-489.

69 Lundtoft C, Afum-Adjei Awuah A, Rimpler J, Harling K, Nausch N, Kohns $\mathrm{M}$ et al. Aberrant plasma IL-7 and soluble IL-7 receptor levels indicate impaired T-cell response to IL-7 in human tuberculosis. PLoS Pathog 2017; 13: e1006425.

70 Rane L, Rahman S, Magalhaes I, Ahmed R, Spangberg M, Kondova I et al. Increased (6 exon) interleukin-7 production after M. tuberculosis infection and soluble interleukin-7 receptor expression in lung tissue. Genes and immunity 2011; 12: 513-522.

71 Lazarevic V, Yankura DJ, DiVito SJ, Flynn JL. Induction of Mycobacterium tuberculosis-specific primary and secondary T-cell responses in interleukin-15-deficient mice. Infect Immunity 2005; 73: 2910-2922.

72 Saito K, Yajima T, Kumabe S, Doi T, Yamada H, Sad S et al. Impaired protection against Mycobacterium bovis bacillus Calmette-Guerin infection in IL-15-deficient mice. J Immunol 2006; 176: 2496-2504.

73 Umemura M, Nishimura H, Hirose K, Matsuguchi T, Yoshikai Y. Overexpression of IL-15 in vivo enhances protection against Mycobacterium bovis bacillus Calmette-Guerin infection via augmentation of NK and T cytotoxic 1 responses. J Immunol 2001; 167: 946-956.

74 Chandrashekara S, Anupama KR, Sambarey A, Chandra N. High IL-6 and low IL-15 levels mark the presence of TB infection: A preliminary study. Cytokine 2016; 81: 57-62.

75 Pydi SS, Bandaru AR, Venkatasubramanian S, Jonnalagada S, Valluri VL. Vaccine for tuberculosis: up-regulation of IL-15 by Ag85A and not by ESAT-6. Tuberculosis 2011; 91: $136-139$.

76 Moreira-Teixeira L, Redford PS, Stavropoulos E, Ghilardi N, Maynard CL, Weaver CT et al. T Cell-Derived IL-10 Impairs Host Resistance to Mycobacterium tuberculosis Infection. J Immunol 2017; 199: 613-623.

77 Turner J, Gonzalez-Juarrero M, Ellis DL, Basaraba RJ, Kipnis A, qOrme IM et al. In vivo IL-10 production reactivates chronic pulmonary tuberculosis in C57BL/6 mice. J Immunol 2002; 169: 6343-6351.

78 Cyktor JC, Carruthers B, Kominsky RA, Beamer GL, Stromberg P, Turner J. IL-10 inhibits mature fibrotic granuloma formation during Mycobacterium tuberculosis infection. J Immunol 2013; 190: 2778-2790.

79 Beamer GL, Flaherty DK, Assogba BD, Stromberg P, GonzalezJuarrero $\mathrm{M}$, de Waal Malefyt $\mathrm{R}$ et al. Interleukin-10 promotes Mycobacterium tuberculosis disease progression in CBA/J mice. $\mathrm{J}$ Immunol 2008; 181: 5545-5550.

80 Barnes PF, Lu S, Abrams JS, Wang E, Yamamura M, Modlin RL. Cytokine production at the site of disease in human tuberculosis. Infect Immunity 1993; 61: 3482-3489.

81 Huard RC, Chitale S, Leung M, Lazzarini LC, Zhu H, Shashkina E et al. The Mycobacterium tuberculosis complex-restricted gene cfp32 encodes an expressed protein that is detectable in tuberculosis patients and is positively correlated with pulmonary interleukin- 10 . Infect Immunity 2003; 71: 6871-6883.

82 Almeida AS, Lago PM, Boechat N, Huard RC, Lazzarini LC, Santos AR et al. Tuberculosis is associated with a down-modulatory lung immune response that impairs Th1-type immunity. J Immunol 2009; 183: 718-731

83 Bonecini-Almeida MG, Ho JL, Boechat N, Huard RC, Chitale S, Doo $\mathrm{H}$ et al. Down-modulation of lung immune responses by interleukin-10 and transforming growth factor beta (TGF-beta) and analysis of TGF-beta receptors I and II in active tuberculosis. Infect Immunity 2004; 72: 2628-2634. 
84 Gopal R, Lin Y, Obermajer N, Slight S, Nuthalapati N, Ahmed M et al. IL-23-dependent IL-17 drives Th1-cell responses following Mycobacterium bovis BCG vaccination. Eur J Immunol 2012; 42: 364-373.

85 Khader SA, Pearl JE, Sakamoto K, Gilmartin L, Bell GK, Jelley-Gibbs DM et al. IL-23 compensates for the absence of IL-12p70 and is essential for the IL-17 response during tuberculosis but is dispensable for protection and antigen-specific IFN-gamma responses if IL-12p70 is available. J Immunol 2005; 175: 788-795.

86 Gallegos AM, van Heijst JW, Samstein M, Su X, Pamer EG, Glickman MS. A gamma interferon independent mechanism of CD4 $\mathrm{T}$ cell mediated control of $\mathrm{M}$. tuberculosis infection in vivo. PLoS Pathog 2011; 7: e1002052.

87 Chen X, Zhang M, Liao M, Graner MW, Wu C, Yang Q et al. Reduced Th17 response in patients with tuberculosis correlates with IL-6R expression on CD4+ T Cells. Am J Respir Crit Care Med 2010; 181: 734-742.

88 Nunes-Alves C, Booty MG, Carpenter SM, Jayaraman P, Rothchild AC, Behar SM. In search of a new paradigm for protective immunity to TB. Nat Reviews Microbiol 2014; 12: 289-299.

89 Singh A, Mohan A, Dey AB, Mitra DK. Inhibiting the programmed death 1 pathway rescues Mycobacterium tuberculosis-specific interferon gamma-producing $T$ cells from apoptosis in patients with pulmonary tuberculosis. J Infect Dis 2013; 208: 603-615.

90 Jurado JO, Alvarez IB, Pasquinelli V, Martinez GJ, Quiroga MF, Abbate $\mathrm{E}$ et al. Programmed death (PD)-1:PD-ligand 1/PD-ligand 2 pathway inhibits $T$ cell effector functions during human tuberculosis. J Immunol 2008; 181: 116-125.

91 Gao L, Bai L, Liu J, Lu W, Wang X, Li X et al. Annual risk of tuberculosis infection in rural China: a population-based prospective study. Eur Respir J 2016; 48: 168-178.

92 De Groote MA, Higgins M, Hraha T, Wall K, Wilson ML, Sterling DG et al. Highly multiplexed proteomic analysis of quantiferon supernatants to identify biomarkers of latent tuberculosis infection. J Clin Microbiol 2017; 55: 391-402.

93 Sandhu G, Battaglia F, Ely BK, Athanasakis D, Montoya R, Valencia T et al. Discriminating active from latent tuberculosis in patients presenting to community clinics. PLOS ONE 2012; 7: e38080.

94 Che N, Cheng J, Li H, Zhang Z, Zhang X, Ding Z et al. Decreased serum 5-oxoproline in TB patients is associated with pathological damage of the lung. Clin Chim Acta 2013; 423: 5-9.

95 Weiner J 3rd, Parida SK, Maertzdorf J, Black GF, Repsilber D, Telaar A et al. Biomarkers of inflammation, immunosuppression and stress with active disease are revealed by metabolomic profiling of tuberculosis patients. PLOS ONE 2012; 7: e40221.

96 Lai CK, Ho S, Chan CH, Chan J, Choy D, Leung R et al. Cytokine gene expression profile of circulating CD4+ T cells in active pulmonary tuberculosis. Chest 1997; 111: 606-611.

97 Woodworth JS, Aagaard CS, Hansen PR, Cassidy JP, Agger EM, Andersen P. Protective CD4 T cells targeting cryptic epitopes of Mycobacterium tuberculosis resist infection-driven terminal differentiation. J Immunol 2014; 192: 3247-3258.

98 Aagaard CS, Hoang TT, Vingsbo-Lundberg C, Dietrich J, Andersen P. Quality and vaccine efficacy of CD4+ T cell responses directed to dominant and subdominant epitopes in ESAT- 6 from Mycobacterium tuberculosis. J Immunol 2009; 183: 2659-2668.

99 Seder RA, Darrah PA, Roederer M. T-cell quality in memory and protection: implications for vaccine design. Nat Rev Immunol 2008; 8: 247-258.

100 Harari A, Rozot V, Bellutti Enders F, Perreau M, Stalder JM, Nicod LP et al. Dominant TNF-alpha+ Mycobacterium tuberculosis-specific CD4+ $\mathrm{T}$ cell responses discriminate between latent infection and active disease. Nat Med 2011; 17: 372-376.

101 Jeong YH, Jeon BY, Gu SH, Cho SN, Shin SJ, Chang J et al. Differentiation of antigen-specific $T$ cells with limited functional capacity during Mycobacterium tuberculosis infection. Infect Immunity 2014; 82: 132-139.

102 Petruccioli E, Petrone L, Vanini V, Sampaolesi A, Gualano G, Girardi $\mathrm{E}$ et al. IFNgamma/TNFalpha specific-cells and effector memory phenotype associate with active tuberculosis. J Infect 2013; 66: 475-486.

103 Day CL, Abrahams DA, Lerumo L, Janse van Rensburg E, Stone L, O'Rie $T$ et al. Functional capacity of Mycobacterium tuberculosisspecific $T$ cell responses in humans is associated with mycobacterial load. J Immunol 2011; 187: 2222-2232.
104 Qiu Z, Zhang M, Zhu Y, Zheng F, Lu P, Liu H et al. Multifunctional CD4 $T$ cell responses in patients with active tuberculosis. Sci Rep 2012; 2: 216.

105 Sutherland JS, Adetifa IM, Hill PC, Adegbola RA, Ota MO. Pattern and diversity of cytokine production differentiates between Mycobacterium tuberculosis infection and disease. Eur J Immunol 2009; 39: 723-729.

106 Caccamo N, Guggino G, Joosten SA, Gelsomino G, Di Carlo P, Titone L et al. Multifunctional CD4(+) T cells correlate with active Mycobacterium tuberculosis infection. Eur J Immunol 2010; 40: 2211-2220.

107 Han Q, Bagheri N, Bradshaw EM, Hafler DA, Lauffenburger DA, Love JC. Polyfunctional responses by human $T$ cells result from sequential release of cytokines. Proc Natl Acad Sci USA 2012; 109: 1607-1612.

108 Evans CM, Jenner RG. Transcription factor interplay in T helper cell differentiation. Brief Funct Genomics 2013; 12: 499-511.

109 Jurado JO, Pasquinelli V, Alvarez IB, Pena D, Rovetta AI, Tateosian NL et al. IL-17 and IFN-gamma expression in lymphocytes from patients with active tuberculosis correlates with the severity of the disease. J Leukoc Biol 2012; 91: 991-1002.

110 Arlehamn CL, Seumois G, Gerasimova A, Huang C, Fu Z, Yue X et al. Transcriptional profile of tuberculosis antigen-specific $T$ cells reveals novel multifunctional features. J Immunol 2014; 193: 2931-2940.

111 Lindestam Arlehamn CS, Gerasimova A, Mele F, Henderson R, Swann J, Greenbaum JA et al. Memory T cells in latent Mycobacterium tuberculosis infection are directed against three antigenic islands and largely contained in a CXCR3+CCR6+ Th1 subset. PLoS Pathog 2013; 9: e1003130.

112 Becattini S, Latorre D, Mele F, Foglierini M, De Gregorio C, Cassotta $\mathrm{A}$ et al. T cell immunity. Functional heterogeneity of human memory $\mathrm{CD} 4(+) \mathrm{T}$ cell clones primed by pathogens or vaccines. Science 2015; 347: 400-406.

$113 \mathrm{Lu}$ LL, Chung AW, Rosebrock TR, Ghebremichael M, Yu WH, Grace PS et al. A functional role for antibodies in tuberculosis. Cell 2016; 167: 433-443 e414.

114 Chambers MA, Gavier-Widen D, Hewinson RG. Antibody bound to the surface antigen MPB83 of Mycobacterium bovis enhances survival against high dose and low dose challenge. FEMS Immunol Med Microbiology 2004; 41: 93-100.

115 Hamasur B, Haile M, Pawlowski A, Schroder U, Kallenius G, Svenson SB. A mycobacterial lipoarabinomannan specific monoclonal antibody and its $F\left(a b^{\prime}\right)$ fragment prolong survival of mice infected with Mycobacterium tuberculosis. Clin Exp Immunol 2004; 138: 30-38.

116 Lopez Y, Yero D, Falero-Diaz G, Olivares N, Sarmiento ME, Sifontes S et al. Induction of a protective response with an IgA monoclonal antibody against Mycobacterium tuberculosis $16 \mathrm{kDa}$ protein in a model of progressive pulmonary infection. Int J Med Microbiol 2009; 299: 447-452.

117 Williams A, Reljic R, Naylor I, Clark SO, Falero-Diaz G, Singh M et al. Passive protection with immunoglobulin $\mathrm{A}$ antibodies against tuberculous early infection of the lungs. Immunology 2004; 111: 328-333.

118 Roy E, Stavropoulos E, Brennan J, Coade S, Grigorieva E, Walker B et al. Therapeutic efficacy of high-dose intravenous immunoglobulin in Mycobacterium tuberculosis infection in mice. Infect Immunity 2005; 73: 6101-6109.

119 Guirado E, Amat I, Gil O, Diaz J, Arcos V, Caceres N et al. Passive serum therapy with polyclonal antibodies against Mycobacterium tuberculosis protects against post-chemotherapy relapse of tuberculosis infection in SCID mice. Microbes Infect 2006; 8: 1252-1259.

120 Olivares N, Leon A, Lopez Y, Puig A, Cadiz A, Falero G et al. The effect of the administration of human gamma globulins in a model of BCG infection in mice. Tuberculosis 2006; 86: 268-272.

121 Zimmermann N, Thormann V, Hu B, Kohler AB, Imai-Matsushima A, Locht $C$ et al. Human isotype-dependent inhibitory antibody responses against Mycobacterium tuberculosis. EMBO Mol Med 2016; 8: 1325-1339.

$122 \mathrm{Li} \mathrm{H}$, Wang XX. Wang B, Fu L, Liu G, Lu Y et al. Latently and uninfected healthcare workers exposed to TB make protective antibodies against Mycobacterium tuberculosis. Proc Natl Acad Sci USA 2017; 114: 5023-5028. 